\title{
Implementasi Ice Breaking dalam Pembelajaran Bahasa Arab bagi Non-Arab
}

\author{
Siti Maisah \\ UIN Sunan Kalijaga Yogyakarta \\ Email: maymaisah94@gmail.com
}

\begin{abstract}
The purpose of this article is to describe how to implementation the ice breaking in learning of Arabic language. Where during this time, to teach Arabic Language almost by conventional method. So cause teach Arabic Language the studies is flat make students feel boored and not attention if the teacher teach of learning. It can to be be change with entering the ice breaking methond in learning procces. Because in implementation of ice breaking, the students invite play and learning. And the other else, implementation this ice breaking can interest of student for more than like Arabic language. Theacher can be this ice breaking one of method for review of learning . and need a remember in implementation ice breaking not set aside the obligation learning. Because maksimal duration of implementation ice breaking is 15 minute. The Method of this research is using the library research. Therefore. In this article writed some example of ice breaking and describe the related with Maharah Lughoh (Language Skill). And result of this research is Any of ice breaking in this research can return the concretation dan also spirit ini learning of Arabic Language, appropriate with kind of maharah lughoh (language skill).
\end{abstract}

Key word: Ice breaking, Arabic language learning, Arabic Language, Language Skill

\begin{abstract}
Abstrak
Artikel ini bertujuan untuk mendeskripsikan ice breaking diimplementasikan dalam pembelajaran bahasa Arab. Selama ini bahasa Arab sering diajarkan dengan cara konvensional. Sehingga menyebabkan pembelajaran bahasa Arab berlangsung datar, membuat siswa bosan dan tidak memperhatikan ketika guru menyampaikan materi pembelajaran. Hal ini dapat dirubah dengan cara memasukkan ice breaking dalam proses pembelajaran. Sebab dalam implementasi ice breaking, siswa diajak bermain sambil belajar. Selain itu, dengan penyampaian ice breaking juga dapat menarik siswa untuk lebih menyukai bahasa Arab. Guru dapat menjadikan ice breaking sebagai salah satu cara untuk meriew pelajaran yang telah disampaikan sebelumnya. Perlu diingat, bahwasanya penyampaian ice breaking tidak boleh mengesampingkan materi pembelajaran yang wajib tersampaikan kepada siswa karena durasi maksimal penyampaian ice breaking yaitu 15 menit. Adapun tujuan utama ice
\end{abstract}


breaking yaitu mengembalikan konsentrasi dan semangat belajar siswa. Penelitian tersebut menggunakan metode penelitian pustaka (library research). Dalam artikel ini ditulis beberapa contoh ice breaking serta dijelaskan pula kaitannya dengan keterampilan bahasa (maharah al-lughah). Adapun hasil dari penelitian ini yaitubebrapa bentuk ice breaking yang dapat mengembalikan konsentrasi dan semangat mempelajari bahasa Arab sesuai dengan jenis keterampilan bahasa (maharah al-lughah) yang dituju.

Kata kunci: Ice Breaking, Pembelajaran Bahasa Arab, Bahasa Arab, Keterampilan Bahasa

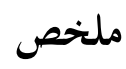

إن غاية هذا البحث وصف كيفية تطبيق كسر الجليد في تعلم اللغة العربية. خلال هذا الوقت، كانت اللغة العربية تدرس في الغالب بالطريقة التقليدية حتى يسبب تعلم اللغة العربية ناقصا ويجعل الطلاب يشعرون بالملل وعدم الاهتمام لما جاء المعلم بمواد تعليمية. وهذا الحال يمكن تغييره بتطبيق كسر الجليد في التعليم. لاسيما فن تنفيذ هذا العمل دعا الطلاب إلى التمتع في أثناء التعلم. فقع تسليم الجليد يفضل الطلاب اللغة العربية. وبهذه الطريقة يمكن المعلم مراجعة المواضع التى بحثت من قبل. واعلم، أن تسليم الجليد يجب ألا يستبعد المواد التعليمية التي يجب نقلها للطلاب. لأن الحد الأقصى لمدة تسليم كسر الجليد هو 15 دقيقة. فللغرض الرئيسي من كسر الجليد هو استعادة التركيز والحماس لتعلم الطلاب، حيث تستخدم هذه الدراسة أساليب البحث المكتبيقي وأحضرت الباحثة الأمثلة على كسر الجليد مع ربط بالمهارات اللغوية، وكذلك نتائج هذه الدراسة. أي شكل من أشكال كسر الجليد يمكن أن يعيد التركيز والحماس لتعلم اللغة العبية وفقًا لنوع المهارات اللغوية المقصودة. الكلمة الرئيسية: كسر الجليد، تعلم اللغة العربية، اللغة العربية، مهارة اللغوية

\section{Pendahuluan}

Pengajaran bahasa Arab di Asia Tenggara umumnya dan di Indonesia khususnya, telah berlangsung selama berabad-abad. Akan tetapi perkembangannya sangat lamban dibanding dengan bahasa asing lainnya. Hal ini disebabkan karena bahasa Arab identik dengan bahasa agama. Sebab dua sumber agama Islam yaitu al-Quran dan hadits menggunakan bahasa Arab. 
Sejauh ini bahasa Arab masih didominasi oleh pandangan bahwa pengetahuan sebagai perangkat fakta-fakta yang harus dihafal. Kelas masih terfokus ada guru sebagai sumber utama pengetahuan dan ceramah menjadi pilihan strategi pembelajaran. Untuk itu diperlukan pendekatan, strategi, dan teknik belajar yang tidak mengharuskan siswa menghafal fakta tetapi sebuah pendekatan, strategi, dan teknik yang mendorong siswa untuk mengkontruksikan dan mendialektikakan pengetahuan mereka. ${ }^{1}$

Oleh karena itu, pembelajaran bahasa Arab juga menuntut kecerdasan setiap guru untuk memahami aspek yang keterkaitan dengan hasil pembelajaran. Yaitu dengan menciptakan teknik-teknik baru dalam pembelajaran bahasa Arab agar siswa menjadi lebih aktif, terampil, mampu menguasai dan mahir dalam pembelajaran bahasa Arab. ${ }^{2}$ Dengan kata lain, guru bahasa dituntut untuk kreatif dan profesional sehingga pembelajaran tidak membosankan dan sukses. Sukses yang dimaksud disini adalah tersampaikannya materi kepada siswa.

Menjadi guru kreatif, profesional, dan menyenangkan dituntut untuk memiliki kemampuan mengembangkan pendekatan dan memilih metode pembelajaran yang efektif. Hal ini penting untuk menciptakan iklim pembelajaran yang kondusif dan menyenangkan. ${ }^{3}$

Pemilihan tersebut disesuaikan dengan kondisi siswa. Baik dari segi jumlah, maupun keadaan siswa. Keadaan siswa yang masih semangat, ataupun sudah mulai bosan. Hal ini penting diperhatikan agar guru dapat menyampaikan materi dengan baik dan siswa dapat menerima materi dengan baik pula. Ketika siswa sudah mulai bosan dengan pembelajaran, guru dapat mengendalikan kelas dengan ice breaking baik ketika mulai pembelajaran, maupun ditengah pembelajaran. Perlu di garis bawahi, bahwasanya penyampaian ice breaking tidak boleh mengganggu materi inti yang harus disampaikan guru kepada siswa. Seperti halnya, ketika siswa disuruh diskusi mengenai suatu materi yang disampaikan oleh guru, tiba-tiba ia memotong kegiatan tersebut dengan

1 Muhajir, Arah Baru Pengajaran Bahasa Arab Filsfat Bahasa, Metode, dan Pengembangan Kurikulum. (Yogyakarta : Fakultas Tarbiyah dan Ilmu Keguruan, 2017). Hal. 216.

${ }^{2}$ Muhajir, Arah Baru Pengajaran Bahasa Arab..., Hal. 220.

3 E Mulyasa, Menjadi Guru Profesional Menciptakan Pembelajaran Kreatif dan Menyenangkan (Bandung: Remaja Rosdakarya, 2011). Hal. 95 
ice breaking. Hal seperti ini yang dapat mengganggu tersampaikannya materi kepada siswa. Sebab proses pembelajaran siswa dapat tidak tuntas karena mereka sedang dalam proses kegiatan pembelajaran.

Dalam ice breaking, guru dapat memasukkan materi pembelajaran yang akan atau telah disampaikan. Sebab dalam penyampaian ice breaking, guru dapat menyampaiakannya dengan materi yang dibutuhkan. Seperti halnya, guru menyampaikan perbedaan kalimat, yaitu isim, fi'il, dan huruf. Guru dapat menugaskan murid untuk estafet bola sambil menyebutkan salah satu mufrodat baik dari kalimatisim, fi'il, ataupun huruf.

Selain itu, Ice breakingjuga dapat mencairkan kondisi siswa yang awalnya bosan ataupun menegangkan menjadi menyenangkan. Siswa dapat bermain sambil belajar. Tanpa mengesampingkan materi-materi inti baik dari buku literatur maupun yang lainnya. Jenis ice breaking bermacam-macam diantaranya yaitu permainan ${ }^{4}$, menyanyi ${ }^{5}$, gerak badan $^{6}$, audio visual ${ }^{7}$, dan story telling. ${ }^{8}$. Guru dapat memilih dan menyesuaikan dengan kondisi kelas yang ia hadapi. Kondisi kelas tersebut meliputi jumlah siswa serta keadaan siswa, keadaan masih semangat atau mulai lelah. Jika siswa masih semangat untuk melanjutkan pembelajran, maka guru dapat langsung menyampaikan materi yang harus diajarkan kemudian diakhir pembelajaran dapat dilakukan ice breaking. Akan tetapi jika siswa sudah lelah, guru dapat melakukan ice breaking terlebih dahulu. Sebelum menyampaikan materi pembelajaran.

Adapun tujuan utama ice breakingyaitu megembalikan konsentrasi dan meningkatkan motivasi siswa dalam mengikuti proses pembelajaran. Menjaga semangat dan stamina siswa adalah hal yang paling penting dilakukan oleh guru. Maka prinsip motivasi menjadi dasar atas pemilihan jenis atau bentuk ice breaking yang tepat. Jika peserta didik mengalami penurunan stamina dan semangat belajar maka dapat

${ }^{4}$ Iva Rifa, Koleksi Games Edukatif di Dalam dan Luar Sekolah. (Yogyakarta: Flash Book, 2012). Hal. 12

${ }^{5}$ Sunarto, Ice Breaking Dalam Pembelajaran Aktif. (Surakarta: Cakrawala Media, 2012). Hal. 43

${ }^{6}$ Sunarto, Ice Breaking...... Hal. 49.

7 Adi Soenarno, Ice Breaker: Don't Be Tegang!! Untuk Pelatihan Manajemen. (Yogyakarta: Andi Publisher, 2007). Hal. 48.

8 Sunarto, Ice Breaking..., Hal. 70. 
mempengaruhi daya serap informasi. Peserta didik yang memiliki motivasi belajar yang tinggi maka mereka dapat memusatkan perhatian saat pembelajaran berlangsung. Sebaliknya jika motivasi peserta didik rendah maka dapat berakibat pada rendahnya ketercapaian tujuan pembelajaran secara optimal. Hal ini sejalan dengan penelitian yang dilakukan peneliti sebelumnya yaitu implementasi ice breaking dalam pembelajaran bahasa Arab tersebut sebagai salah satu alternatif upaya untuk menarik atau mengembalikan perhatian peserta didik dan mendukung kondusifitas belajar. Selain itu, ice breaking juga mampu membuat perubahan yang signifikan prestasi belajar siswa dengan penerapan teknik ice breaking pada pebelajaran bahasa Arab.

Penulis tertarik untuk membahas ice breaking dalam pembelajaran bahasa Arab karena dirasa masih dibutuhkannya referensi bagi guru atau pengajar bahasa Arab. Penggunaan ice breaking dalam pembelajaran dapat menarik siswa untuk lebih termotivasi dan menikmati pembelajaran yang disampaikan oleh guru. Disini penulis membahas peran ice breaking dalam pembelajaran bahasa Arab.

\section{Metode Penelitian}

Penelitian ini menggunakan metode kualitatif dan studi literatur(library research). Dalam penelitian ini, peneliti menggunakan teknik pengumpulan data dengan mencari sumber dari buku, jurnal, dan hasil seminar. Setelah semua data terkumpul, peneliti melakukan analisis data dengan teknik analisis data deskriptif dan interpretasi data, kemudian peneliti memberikan penjelasan secukupnya.

\section{Pembelajaran Bahasa Arab}

Pembelajaran secara umum adalah proses proses interaksi siswa/mahasiswa dengan guru/ dosen dan sumber belajar. ${ }^{9}$

Kegiatan pembelajaran (at-ta'lim at-tadris), yaitu proses yang identik dengan kegiatan mengajar yang dilakukan guru sebagai penyusun kegiatan belajar, agar terjadi kegiatan belajar. Dalam KBBI edisi IV, ditulis bahwa pembelajaran berasal dari kata dasar "ajar" yang ditambah dengan awalan "pe" dan akhiran "an" menjadi pembelajaran", yang memiliki arti proses, perbuatan, cara mengajar atau mengajarkan,

9 Maksudin dan Qoim Nurani, Pengembangan Kurikulum Pembelajaran Bahasa Arab (Teori dan Praktek). (Yogyakarta: Lesfi, 2018). Hal. 5. 
sehingga anak didik mau belajar. ${ }^{10}$ Sedangkan Bahaudin menjelaskan bahwa pembelajaran adalah proses untuk membantu peserta didik agar dapat belajar dengan baik. Kegiatan belajar lebih dari sekedar mengajar tetapi upaya untuk membangkitkan minat, motivasi, dan pemolesan kegiatan belajar agar kegiatan mereka menjadi dinamis. ${ }^{11}$

Jadi pembelajaran adalah proses, perbuatan, cara mengajar atau mengajarkan agar peserta didik mau, berminat, serta termotivasi belajar dengan baik. Guru bertugas sebagai pembentuk atau perancang pembelajaran sehingga kegiatan dapat menjadi kondusif untuk mencapai tujuan pembelajaran. Selain itu, guru dapat menjadi sumber ataupun fasilitator dalam pembelajaran. Dengan demikian, pembelajaran bahasa Arab adalah kegiatan mengajar yang dilakukan secara maksimal oleh guru agar apesera didik yang belajar bahasa Arab tersebut melakukan kegiatan belajar dengan baik, sehingga kondusif untuk mencapai tujuan pembelajaran.

Belajar berbahasa hakikatnya adalah belajar keterampilan berbahasa (maharat al-lughah), yaitu menyimak (maharat al-istima'), berbicara (maharat al-kalam), membaca (maharat al-qiroah), dan menulis (maharat al-kitabah). ${ }^{12}$ Empat keterampilan ini merupakan representasi penguasaan komunikasi sebagai aktivitas yang menyatakan pikiran, ide, keinginan, emosi, dan lainnya untuk memenuhi kebutuhan. Dalam penguasaan empat keterampilan tersebut, sebagian para ahli bahasa berasumsi bahwa kemampuan kebahasaan seseorang hanya ditentukan oleh tingkat penguasaan pada sintaksis (nahwu), dan morfologi (sharaf). Sebagian yang lain menolak pendapat tersebut dan mengatakan bahwa tingkat kemampuan kebahasaan seseorang dipengaruhi oleh penguasaan seseorang terhadap arti kosa-kata (ma'na al-mufrodat). Pendapat mereka ini lebih didasarkan pada penguasaan kamus (makna leksikal) ${ }^{13}$.

Bahasa merupakan media ataupun alat komunikasi. Oleh karena itu, bahasa bukan hanya dipelajari secara teoritis, melainkan juga secara

10 Departemen Pendidikan Nasional, Kamus Besar Bahasa Indonesia, Cetakan XVIII, (Jakarta: Gramedia Pustaka Utama, 2008). Hal. 23.

11 Taufik Bahaudin, Brain Ware Leadership Mastery. (Jakarta: Alex Media Komputindo, 2007). Hal. 116

12 Acep Hermawan, Pembelajaran Keteramilan Berbahasa Arab. (Bandung: Alfabeta, 2018). Hal. 12

13 Syaiful Mustofa, Strategi Pembelajaran Bahasa Arab Inovetif. (Malang: UIN MA Liki Press, 2011). Hal. 1-2 
praktis sesuai fungsinya sebagai media atau alat komunikasi. Dengan digunakan secara praktid maka siswa dapat merasakan bahwa bahasa tidak jauh melainkan dekat dengan kehidupan mereka. Karena dalam kesehariannya dapat menggunaan bahasa tersebut untuk berkomunikasi.

Tujuan pembelajaran bahasa Arab di kelas harus lebih otentik dan bermakna. ${ }^{14}$ Artinya para siswa ditekan dan diarahkan untuk mempelajari dan menggunakan bahasa arab bukan sebatas bahasa yang jauh dari jangkauan mereka. Bahasa harus didekatkan dengan cara memasukkan bahasa Arab dalam kehidupan sehari-harinya. Sehingga mereka terbiasa menggunakan bahasa Arab sebagai alat komunikasi.

Stigma yang berkembang di masyarakat menunjukkan bahwa belajar bahasa Arab masih dianggap sulit. Padahal semua bahasa memiliki kemudahan dan kesulitannya masing-masing. Tergantung pada karakteristik sistem bahasa itu sendiri, baik sistem fonologi, morfologi, sintaksis, maupun semantik.

Sementara itu, tata bahasa Indonesia dianggap lebih mudah karena perbedaan jenis laki-perempuan (mudzakar-muanats) atau tunggal (mufrod), dua (mutsanna), dan plural (jamak). Dalam struktur kalimat tidak dikaidahkan dalam bahasa Indonesia. Namun bagi orang Arab, pengungkapan bunyi konsosnan dinilai sangat sulit karena mereka tidak memiliki konsonan dan vokal.

Pembelajaran bahasa Asing melibatkan sekurang-kurangnya tiga disiplin ilmu, yaitu a) linguistik, b) psikologi, c) ilmu pendidikan. ${ }^{15}$ Linguistik menginformasikan tentang bahasa secara umum dan mengenai bahasa-bahasa tertentu. Perbedaan dalam cara atau penggunaan suatu metode dalam pembelajaran bahasa dipengaruhi pula oleh perbedaan perbedaan pandangan tehadap kakekat bahasa, cara menganalisa, dan mendeskripsikan bahasa. ${ }^{16}$ Terdapat beberapa teori yang ditawarkan oleh ahli bahasa diantaranya yaitu:

${ }^{14}$ Nazri Syakur, Revolusi Metodologi, PembelajaranBahasa Arab dari Pendekatan Komunikatif ke Komunikatif Kabiumi. (Yogyakarta: Pedagogi). Hal. 94

${ }^{15}$ Chaedar Alwasilah, Metodologi Pembalajaran Bahasa Arab. (Bandung: Remaja Rosdakarya, 2011). Hal. 33

16 Wa Muna, Metodologi Pembalajaran Bahasa Arab Teori dan Aplikasi. ( Yogyakarta: Teras, 2011), Hal. 18 
Mahmud Yunus mengemukakan bahwa "dalam mengajarkan bahasa Arab ada dua teori yakni teori kesatuan (نظرية الوحدة (نظوع) dan teori bagian-bagian (نظرية الفروع). ${ }^{17}$

Moh. Matsna mengatakan bahwa: dalam pembelajara bahasa Arab dikenal adanya dua teori (system) pengajaran yaitu نظرية الوحدة (all in one system), yaitu sistem yang memandang bahasa adalah satu kesatuan yang utuh tidak terpisah-pisah, dan نظرية الفروع yaitu teori yang memandang bahwa bahasa terdiri dari beberapa cabang. ${ }^{18}$

Dari dua pendapat diatas dapat diketahui bahwa dalam teori pembelajran bahasa Arab dikenal dua system pembelajaran. Teori pertama memandang bahwa bahasa berhubungan erat antara materi satu dengan yang lainnya, serta bukan terdiri dari beberapa bagian. Dan teori kedua memandang bahawa bahasa Arab terdiri dari beberapa bagian (cabang-cabang).

Pembelajaran bahasa Arab sangat menghendaki keterlibatan peserta didik secara langsung. Oleh karena itu, hendaknya diterapkan model pembelajaran interaktif yaitu "model pembelajaran yang melibatkan siswa secara aktif dan pasif"19 disini posisi peserta didik dapat menjadi subyek dan objek pendidikan.

Model pembelajaran interaktif ini dimaksudkan untuk memperkenalkan kepada peserta didik mengenai pengetahuan dan materi-materi tertentu yang diajarkan kepada mereka. Serta mereka diberi kesempatan untuk mengatasi permasalahan secara bersama-sama. Tujuan utama model tersebut adalah memberikan focus terhadap permasalahn yang akan dipechakan. Sehingga tujuan pembelajaran dapat tercapai sesuai yang diinginkan. Apabila model pembelajaran interaktif dan aktif ini dapat dilakukan di kelas. Maka kelas akan lebih hidup karena dipenuhi dengan ide dan gagasan peserta didik dalam bentuk interaktif. Keterlibatan peserta didik dalam pembelajaran tersebut lambat-laun akan kemampuan untuk berkomunikasi dengan bahsa Arab secara lisan dengan teratur.

Hal. 26

${ }_{17}$ M. Yunus, Metodik Khusus Bahasa Arab. (Jakarta: PT. Hidakarya Gung, 1993).

${ }_{18}$ Moh. Matsna HS., Metodik Pengajaran Bahasa Arab. (Jakarta: Bulan Bintang, 1964). Hal. 3

${ }^{19}$ Mukhtar, Desain Pembelajaran Pendidikan Agama Islam. (Jakarta: CV. Misaka Galiza, 2003). Hal. 145 
Selain itu, pembelajaran aktif atau interaktif tersebut dapat mendorong peserta didik untuk mengeluarkan ide atau gagasan yang terpendam. Serta dapat membangkitkan motivasi dan minat siswa dalam belajar.

Terdapat bebrapa alasan peserta didik cenderung melupakan apa yang mereka dengar. Salah satu penyebab yang menarik adalah perbedaan kecepatan bicara pengajar dengan tingkat kecepatan kemampuan siswa mendengar. ${ }^{20}$ Kebanyakan guru berbicara kurang lebih 100-200kata per menit. Namun, banyak kata yang dapat didengar siswa tergantung bagaimana mereka mendengar. Jika siswa benar-benar konsentrasi, mereka akan mendengar sekitar 50-100 kata per menit, atau setengah dari yang dikatakan oleh guru. Hal ini disebabkan karna peserta didik mendengar sambil berfikir. Selain itu, peserta didik tidak semua mendengarkan dengan baik, kecuali penyampaian pembelajaran menarik.

\section{Ice Breaking}

Ice breaking dari segi arti kata ice diterjemahkan es. ${ }^{21}$ Sedangkan breaking dari asal kata break dalam bahasa Inggris yang terjemahannya dalam bahasa Indonesia memecahkan.22 Ini merupakan penggabungan dua kata yang jika digabungkan dapat diterjemahkan memecahkan kebekuan dari makna tekstual terjemahan "memecah es". Yang diamksud memecah es adalah memecah kebekuan atau kevakuman dari pembelajaran yang telah berlangsung.

Menurut Susan Healthfield:

An ice breaker is an activity, game, or event that is used to welcome ant warm up the conversation among participants in a meeting, training class, team building session, or another event. Any event that require people to comfourtably interact with each other. ${ }^{23}$

${ }^{20}$ Mel Sibermen, Active Learning 101 Strategi Pembelajaran Aktif. (Yogyakarta : Pustaka Insan Madani, 2009). Hal. 2.

${ }^{21}$ Hasan Shadily, Kamus Inggris Indonesia. (Jakarta: PT. Gramedia, 1982). Hal. 309.

${ }^{22}$ Hasan Shadily, Kamus Inggris Indonesia ..., Hal. 79.

23 Susan M. Heathfield, "What Is An Ice Breaker?", Http://Www.Thebalance.Com/What-Is-An-Ice-Breaker-1918156, Diakses Hari Sabtu 4 Desember 2018 Pukul 13.00 WIB. 
Jadi ice breaking merupakan suatu aktivitas/kegiatan dengan durasi waktu yang pendek dalam suatu acara yang bertujuan agar peserta acara dapat saling mengenal antara satu dengan yang lain dan merasa nyaman dengan lingkungan barunya (dalam pelatihan tersebut).

Ice breaking di awal pembelajaran memberikan semangat kepada siswa sebelum pembelajaran dimulai. Guru memberikan ice breaking sebelum dimulainya pembelajaran memberikan kesan menarik dan menyenangkan. Saat guru mengajak siswa untuk melakukan ice breaking siswa akan semangat dan antusias. Sedangkan ice breaking ditengah pembelajaran bertujuan untuk mengambalikan konsentrasi siswa yang sudah menurun. Hal ini dilakukan karena siswa ditengah proses pembelajaran terlihat bosan, mengantuk, dan malas. Konsentrasi terwujud dari engaturan lingkungan belajar, agar siswa merasa rileks dalam proses pembelajaran. Setelah diberikan ice breaking siswa akan kembali memperhatikan materi pelajaran yang disampaikan oleh guru. Pembelajaran yang menyenangkan mendorong siswa lebih kreatif. Siswa akan berani mengungkapkan ide dan gagasannya sehingga pembelajaran akan menjadi lebih hidup. ${ }^{24}$

Hal yang menyebabkan penggunaan ice breaking dalam pembelajaran adalah untuk membuat siswa senang dan menikmati pembelajaran. Sebab di dalam ice breaking guru dapat menyajikannya sesuai dengan materi yang akan atau telah disampaikan kepada siswa. Sehingga siswa menikmati pembelajaran dan materi yang disampaikan guru dapat tersampaikan kepada murid. Tidak dipungkiri, bahwasanya penguasaan materi dan media guru bahasa. Dapat mempengaruhi daya tarik dan tangkap para siswa. Jika pembelajaran bahasa hanya disampaikan seperti ceramah, maka siswa banyak yang akan merasa bosan dan ingin jam pelajaran segera berakhir.

Menurut Goleman dalam Bobbi De Porter menyatakan bahwa kondisi ketika otak manusia menerima ancaman atau tekanan, kapasitas syaraf untuk berpikir rasional akan mengecil dan otak dibajak secara emosional. ${ }^{25} \mathrm{Hal}$ ini secara empiris dapat disaksikan dalam pembelajaran

${ }^{24}$ Ayu Novia Kurniasih Dan Dedy Hidayatullah Al-Arifin, "Penerapan Ice Breaking (Penyegar Pembelajaran) untuk Meningkatkan Hasl Belajar IPA Siswa Kelas VIIIA Mts An-Nur Pelopor Bandar Jaya Tahun Pelajaran 2013/2014". Hal. 34.

${ }^{25}$ Bobbi De Porter Dan Mike Hemmacki, Quantum Learning: Membiasakan Belajar Nyaman dan Menyenangkan, (Bandung: Kaifa, 2001). Hal. 22. 
tradisional. Hal yang biasa dilakukan oleh guru pada saat perhatian peserta didik mulai melemah adalah dengan meninggikan suara atau memukul meja sehingga menimbulkan suasana pembelajaran yang menegangkan. Bila suasana belajar tidak lagi nyaman akan berimbas pada stamina emosi dan kecerdasan berpikir siswa. Jika proses ini dibiarkan, maka pembelajaran tidak akan efektif serta susanan tidak kondusif.

Konsep ice breaking ini tidak berarti bahwa tidak ada cara lain untuk membuat pembelajran menjadi menarik. Tentu terdapat banyak cara-cara lain yang dapat digunakan. Akan tetapi dalam konteks pembelajaran ice breaking dimaksudkan sebagai salah satu strategi pendukung pembelajaran. Oleh sebab itu, mempelajari secara lebih dalam tentang ice breaking adalah sesuatu yang akan menarik bagi para guru yang memiliki kemauan serta semangat yang tinggi untuk menciptakan susanan belajar yang kondusif dan kreatif.

Bhayu setiawan mengungkapkan bahwa seni mengajar dengan ice breaker dapat dimanfaatkan untuk pembelajaran efektif. Mengajar merupakan seni dalam konteks metoda yang disampaikan kepada peserta didik. Guru harus memiliki keterampilam menciptakan suasana kelas dan pembelajaran yang menyenangkan serta tidak menjenuhkan. Ice breaker adalah seni penyemangat belajar untuk fun learning. ${ }^{26}$

Kadangkala konsep materi pembelajaran masih berbentuk abstrak. Untuk memperoleh pemahaman abstraksi dari konsep yang benar agar sesuai dengan hasil yang diharapkan, maka hal ini prlu dikaji lebih lanjut dalam prinsip-prinsip ice breaking, macam-macamnya dan hal-hal yang perlu diperhatikan ataupun dihindari dalam ice breaking, agar apa yang menjadi tujuan dapat tercapai.

Beberapa pakar berpendapat bahwa memory dan daya tangkap otak manusia itu memiliki kemampuan konsentrasi terbatas. Bunda Lucy dan ade julius $\mathrm{R}$ mengungkakan bahwa terdapat rentang fokus yang berbeda pada tingkat usia seseorang otak tidak dapat dipaksa untuk melakkan fokus yang lam.Beberapa kategori kisaran rentang waktu berdasarkan usia tersebut; usia 5 tahun kisaran waktu fokusnya 5 menit, usia 15 tahun kisaran waktu fokusnya 15 menit, sedangkan rentang usia

${ }^{26}$ Bhayu Sulistiawan, Ice Breaker Untuk Pembelajaran Aktif. (Surakarta: Yumna Pustaka, 2013). Hal. 33. 
antara 30 tahun hingga 60 tahun kisaran waktu fokusnya 30 menit. ${ }^{27}$ Dari sini dapat disimpulkan bahwa kisaran waktu maksimal agar otak tidak mengalami penekaanan adalah 30 menit.

Penggunaan ice breaking dalam pembelajaran akan sangat membantu dalam menciptakan suasana pendidikan yang bermakna, menyenangkan kreatif, dinamis dan dialogis. Suasana pendidikan yang menyenangkan memang secara sebab akibat akan mendorong siswa untuk bisa lebih kreatif dan dinamis. Siswa juga akan semakin berani untuk mengemukakan ide dan gagasannya sehingga pembelajaran lebih dialogis. ${ }^{28}$ dengan pengunaan ice breaking maka seluruh siswa akan mendapat peran penting, karena mereka semua terlibat di dalamnya. Sehingga siswa dapat belajar dengan berperan aktif dalam pembelajaran. Tujuan penggunaan Ice Breaking

Arti penting ice breaker adalah strategi untuk menghilangkan kejenuhan, menarik kembali perhatian peserta terhadap materi yang disampaikan oleh pembicara. Jika embicara dapat menarik kembali perhatian peserta, maka materi yang disampaikannya menarik serta peserta menikmati penyampaian materi tersebut. selain itu, terjadi komunikatif yag efektif selama kegiatan berlangsung. ${ }^{29}$

Ice breaker berfungsi mengatur agar peserta tidak hanya menjadi sosok patung, diam, dan mendengar. ice breaker akan membuat peserta menjadi mau berfikir, berkreasi, berimajinasi sesuai keinginan dan kemampuannya. Jika peserta telah terkondisikan maka materi yang disampaikan akan diikutinya dengan seksama. ${ }^{30}$

Ice breaker merupakan peralihan situasi dari yang membosankan, membuat ngantuk, jenuh, dan tegang, menjadi rileks bersemangat, serta adanya perhatian dan rasa senang untuk mendengarkan atau melihat pembicara di depan kelas atau ruangan. ${ }^{31}$

Ketegangan biasanya diakibatkan oleh :32

27 Bunda Lucy dan Ade Julius R, Dahsyatnya Brain Smart Teaching. (Jakarta: Penebar Plus, 2012). Hal. 50.

28 Sunarto, Ice BreakerUntuk Pembelajaran Aktif. (Surakarta: Cakrawala Media ,2012). Hal. 2-11.

${ }^{29}$ M. Zainuri Nur, Ice Breaker! (Yogyakarta: Laksana, 2010). Hal. 13.

${ }^{30}$ M. Zainuri Nur, Ice Breaker!..., Hal. 14.

${ }^{31}$ M. Zainuri Nur, Ice Breaker!..., Hal. 14.

32 Adi Soenarno, Ice Breaker: Permainan Atraktif - Edukatif Untuk Pelatihan Manajemen. (Yogyakarta: Andi, 2005). Hal. 1. 
a. Pembicara tegang

b. Tidak ada rasa humor

c. Cara membawakan materi tidak menarik

d. Ungkapan pembicara yang disampaikan pembicara monoton

e. Disampaikan pada kondisi yang tidak tepat (mood jelek), peserta dalam kondisi lelah, kantuk, serta sibuk tetapi dipaksakan untuk hadir

f. Materi yang disampaikan tidak jelas

g. Suara terlalu pelan ataupun keras

h. Tempat tidak kondusif

i. Waktu pelaksanaan terlalu lama

Ketegangan akan menyulitkan peserta untuk menerima materi yang sedang dibahas, memunculkan ketidak senangan terhadap kondisi, bahkan dapat mengakibatkan stress pada fase yang parah. ${ }^{33}$

Untuk memfokuskan kembali perhatian murid. Biasanya guru konvensional menggunakan intonasi tinggi ataupun memukul meja dengan keras. Hal tersebut justru membuat suasana menjadi lebih parah.

Ice breaker digunakan sebagai daya pembangkit energi (energizer). Energizer adalah permainan yang digunakan ketika peserta tidak bersemangat. $^{34}$ Ketika pembelajaran tidak kondisional, energizer dibutuhkan dalam proses pembelajaran.

\section{Urgensi Ice Breaking dalam Pembelajaran}

Darmansyah menjelaskan bahwa dalam pembelajaran efektif jika peserta didik dalam keadaan gembira. Kegembiraan dalam belajar sangat mempengaruhi pencapaian hasil belajar peserta didik. Dapat dikatakan bahwa kecerdasan emosional memberikan kontribusi yang sangat signifikan terhadap kecerdasan intelektual. Banyak cara untuk memberikan semangat kepada peserta didik diantaranya ice breaking yang disisipkan dalam proses pembelajaran. ${ }^{35}$ Dengan menggunakan ice breaking dalam pembelajaran maka siswa akan memperoleh pembelajaran yang efektif serta dapat terdorong untuk semangat dalam mengikuti proses pembelajaran.

\footnotetext{
${ }^{33}$ Adi Soenarno, Ice Breaker: ..., Hal. V.

${ }^{34}$ Sunarto, Ice Breaking..., Hal. 2

${ }^{35}$ Sunarto, Ice Breaking..., Hal. 4
} 
Mac Lean menyatakan bahwasanya ketika otak berada pada situasi tertekan, otak berada pada mode bertempur. Orang yang dapat berkonsentrasi lebih baik daripada biasanya, dia akan dapat memberikan hasil yang lebih pula. Sekolah yang menyenangkan yakni praktek Hak Asasi Manusia pada anak, sebenarnya mudah diajarkan dan dipaktekkan. Anak diperlakukan sesuai dengan tumbuh kembangnya, bebas dari rasa takut dan ancaman. Sekolah merupakan salah satu tempat pembelajaran bagi anak. Mereka memiliki ruang ekspresi yang terbuka lebar. ${ }^{36}$ Dengan demikian, peserta didik tidak akan bebas apabila proses belajar penuh dengan tekanan. Pembelajaran yang baik adalah pebelajaran yang disesuaikan dengan karakteristik peserta didik.

UU RI nomor 2 pasal 40 ayat 2 tahun 2003 tentang Sistem Pendidikan Nasional berbunyi:

"Guru dan tenaga kependidikn berkewajiban:

a. Menciptakan suasana pendidikan yang bermakna, menyenangkan, kreatif, dinamis, dan dialogis

b. Mempunyai komitmen secara professional untuk meningkatkan mutu pendidikan

c. Memberi teladan dan menjaga nama baik lembaga, profesi, dan kedudukan sesuai dengan kepercayaan yang diberikan kepadanya." ${ }^{37}$

\section{Prinsip-Prinsip Ice Breaking}

Segala sesuatu tentu memiliki petunjuk teknis dan prinsip tertentu, agar tujuannya terpenuhi. Adapun prinsip-prinsip khusus ice breaking dalam penerapannya adalah sebagai berikut:

a. Sebagai penyeimbang antara otak kanan dan otak kiri. Prinsip ini menjadi landasan agar guru tidak memberikan ice breaking yang sulit. Bahkan mereka merasa terbebani karena sulitnya ice breaking yang diberikan.

b. Dilakukan ketika jeda materi saat muncul kejenuhan. Durasi jeda materi, dapat dimanfaatkan untuk mengisinya dengan ice breaking agar siswa kembali semangat mengikuti materi yang disampaikan

${ }^{36}$ Anna Farida, Dkk, Sekolah yang Menyenangkan: Metode Keatif Mengajar Dan Mengembangkan Karakter Siswa. (Bandung: Nuansa, 2012). Hal. 37.

${ }^{37}$ Sunarto, Ice Breaking..... Hal. 6. 
oleh guru. Apabila semangat mereka kembali, maka materi dapat diterima dengan baik serta tujuan pembelajaran dapat tercapai.

c. Bentuk pendekatan kepada peserta didik dan bukan show. Hal yang harus diingat adalah pemateri informasi bukanlah orang yang sedang melakukan show melainkan lebih seperti fasilitator mentransfer informasi/menyajikan materi agar lebih mudah dipahami peserta didik. Maka ice breaking disajikan dengan prinsip mampu menciptakan suasana penyegaran dan interaktif dengan pesrta. Materi/informasi akan mudah diterima apabila terdapat interaksi yang intensif, luwes, tidak kaku, dan terkesan dekat/akrab dengan peserta. ${ }^{38}$

Dengan demikian, bila ice breaking diterapkan sesuai prinsip diatas dapat berfungsi sebagai penyeimbang, penyegaran, relaksasi yang diharapkan dapat menarik perhatian kembali. Komunikatif interaktif yang terjadi antara pihak yang terlibat dalam proses belajar diharapkan muncul dan mendukung terjadinya iklim yang kondusif. Sehingga kebosanan/ kelelahan/ kejenuhan dengan langkah sederhan yaitu melalui kosep ice breaking yang diterapkan sesuai dengan prinsipnya.

Sunarto menyempurnakan tentang prinsip dalam menerapkan ice breaking diantaranya yaitu penerapan ice breaking dalam proses pembelajaran perlu mempertimbangkan beberapa prinsip pokok, diantaranya yaitu;

a) Efektivitas

Jenis ice breaking yang sekiranya membuat pembelajaran tidak kondusif dalam situasi tertentu hendaknya dihindari. Seperti jenis ice breaking gerak badan yaitu kepala pundak tidak cocok diterpkan pada kondisi kelas yang sempit dan jumlah siswa yang banyak. Atau jenis ice breaking yang menggunakan media lain sehingga menyebabkan basah atau menyisakan sampah kerts kecil dalam ruang kelas yang berkarpet. Prinsip ini menekankan agar konsep ice breaking dimanfaatkan sesuai dengan situasi dan kondisi yang mendukung.

b) Motivasi

Tujuan utama ice breaking adalah meningkatkan motivasi siswa dalam mengikuti proses pembelajaran. Menjaga semangat dan stamina siswa adalah hal yang paling penting dilakukan. Maka

${ }^{38}$ David Pranata, Communication Made Easy. (Jakarta: Elexmedia, 2016). Hal. 18. 
prinsip motivasi adalah menjadi dasar atas pemilihan jenis atau bentuk ice breaking yang tepat. Jika peserta didik mengalami penurunan stamina dan semangat belajar maka daat mempengaruhi daya serap informasi. Peserta didik yang memiliki motivasi belajar yang tinggi maka mereka dapat memusatkan perhatian saat pembelajaran berlangsung. Sebaliknya jika motivasi peserta didik rendah maka dapat berakibat pada sendahnya ketercapaian tujuan pembelajaran secara optimal.

c) Sinkronized

Ice breaking yang dipilih akan lebih baik jika sesuai dengan materi yang dibahas aat pembelajaran berlangsung. Penentuan sinkrinisasi antara informasi/materi yang akan disampaikan dengan ice breaking yang dipilih menjadi kewenangan guru sebagai fasilitator pembelajaran. Dengan demikian ice breaking akan mempunyai daya penguat dan efek mudah diingat oleh peserta didik dan menjadi strategi pembelajaran lebih menarik/ mengembalikan perhatian peserta didik karena telah disiapkan secara baik dan terencana.

d) Tidak berlebihan

Ice breaking merupakan kegiatan yang menyenangkan bagi peserta didik, agar mereka termotivasi untuk mengikuti pembelajaran. Maka yang harus diingat adalah jangan sampai penggunaan ice breaking menjadi pokok kegiatan yang berlebihan serta akan mengaburkan tujuan pembelajaran. Selain itu, harus mempertimbangkan waktu pelajaran agar seimbang antara tersampaikannya materi dengan penenerapan ice breaking dalam proses kegiatan tersebut.

e) Tepat situasi

Prinsip aituasional penerapan ice breaking hendaknya dilaksanankan dengan tepat. Ice breaking yang dilaksanakan serampangan akan dikhawatirkan akan merusak situasi yang sudah kondusif. Misalnya saat peserta didik menjalankan tugas atau diskusi yang diberikan oleh guru, tiba-tiba guru memberikan ice breaking. Tentu situasi akan membingungkan dan menjadikan proses pengerjaan tugas menjadi tidak fokus kembali. Oleh sebab itu, guru harus memiliki keterampilan membaca situasi pembelajaran agar peralihan antar jeda materi yang membutuhkan ice breaking dapat dilaksanakan dengan tepat. 
f) Tidak mengandung unsur SARA

Unsur sara ynag dimaksud adlaah menyinggung peserta didik baik secara fisik maupun nofisik. Ice breaking yang diberikan kepada siswa hendaknya yang mengandung nilai positif terhadap rasa kesatuan dan persatuan. Hal yang mengandung unsur membedakan atau menghina suku, agama, ras, dan antar golongan harus dihindari.

g) Tidak mengandung unsur pornografi

Banyak seklai pilihan ice breaking yang sangat mearik bagi guru. Akantetapi sebagai pendidik hendaknya memiliki jenis ice breaking yang edukatif, sopan dan tidak mengandung unsur pornografi. ${ }^{39}$

\section{Macam-macam model ice breaking}

Apabila diurai tentang macam-macam ice breaking bisa jadi akan bermunculan jenis dan bentuknya yang berjumlah ratusan macam bahkan bisa ribuan. Sebagian ahli mengelompokkan dalam beberapa kategori dasar sesuai dengan teknis dalam penyampaian/penerapannya model ice breaking antara lain:

a. Jenis tepuk tangan

Tepuk tangan sebagai ice breaking sangat efektif mengkonsentrasikan peserta didik sebelum proses pembelajaran dimulai. Selain itu, juga berguna untuk mengkondisikan peserta didik agar fokus kembali. Teknik ice breaking tepuk tangan cukup mudah dan dapat langsung diterapkan tanpa memerlukan persiapan panjang. ${ }^{40}$

b. Games atau permainan

Vygosty menyatakan bahwa bermain mempunyai peran langsung terhadap perkembangan kognisi anak. Menurut Andang Ismail, fungsi permainan edukatif yaitu:

a) Memberikan ilmu pengetahuan kepada anak melalui bermain sambil belajar

b) Menciptakan lingkungan bermain yang menarik dan menyenangkan

c) Meningkatkan kualitas belajar anak baik kemampuan motorik, kognitif, bahasa, dan sosisal. ${ }^{41}$

39 Sunarto, Ice Breaker...., Hal.105-107.

40 Sunarto, Ice Breaker..., Hal. 105-7.

${ }^{41}$ Iva Rifa, Koleksi Games Edukatif di Dalam dan Luar Sekolah. (Yogyakarta: Flash Book, 2012), Hal. 12. 
Selain itu, games dapat membangun ikatan dan kepedulian terhdap pelajaran. Terkadang peserta didik merasakan kebosanan sehingga tidak peduli terhadap pelajaran. Adanya games peserta didik akan kembali fokus terhadap penyampaian materi. ${ }^{42}$

c. Gerak badan

Ice breaking gerak badan bertujuan untuk menjadikan darah lancar setelah beberapa lama berdiam diri dalam aktivitas belajar. Proses berpikirpun akan menjadi lebih keatif dan segar. ${ }^{43}$

d. Audio visual

Jenis yang paling banyak pilihan yang dapat digunakan pada proses pembelajaran, baik di awal pembelajaran, saat kegiatan inti maupun akhir proses pembelajaran. Film gerak suara atau video yang lucu, inspiratif atau memotivasi siswa untuk belajar lebih giat. ${ }^{44}$

e. Story telling

Bercerita sebgai ice breaking adalah menyampaikan sebuah kisah nyata berdasarkan kenyataan atau bersifat fiksi. Cerita harus mengandung teladan. ice breaking Story telling bermanfaat untuk: ${ }^{45}$

a) Menambah daya kreatifitas dan imajinasi.

b) Menambah wawasan, terutama jika kisah berasal dari negara atau budaya ain

c) Meningkatkan kemampuan keakraban emosi antara guru dan peserta didik.

f. Menyanyi

Menyanyi adalah salah satu ice breaking yng paling mudah dan disukai. Dalam ice breaking mnyanyikan lagu yang sebagai acuan yaitu :yang penting happy". Ice breaking bernyanyi mengharuskan ketepatan notasi atau nada. ${ }^{46}$

\section{Ice Breaking dalam Pembelajaran Bahasa Arab}

Ice breaking merupakan kegiatan atau aktivitas yang melibatkan anggota badan, dan membuat siswa bergerak. Dengan dilaksanakannya ice breaking, siswa tidak hanya duduk diam mendengarkan materi yang

42 Sigit Setyawan, Kelas Asyik Dengan Games : 30 Games Untuk Pembelajaran. (Jakarta: Gramedia, 2015), Hal. Xi.

43 Sunarto, Ice Breaking..., Hal. 49.

${ }^{44}$ Adi Soenarno, Ice Breaker: ...., Hal. 48.

45 Sunarto, Ice Breaking..., Hal. 70.

${ }^{46}$ Sunarto, Ice Breaking..., Hal. 43. 
disampaikan oleh guru. Dalam pelaksanaan ice breaking siswa berperan aktif di dalamnya. Sebab pelaksana sentral didalam ice breaking yaitu siswa. guru hanya berperan sebagai fasilitator yang memberi petunjuk dan contoh sebelum pelaksanaan ice breaking.

Meskipun tidak semua ice breaking melibatkan anggota badan, tetapi guru dapat mengembangkan sekreatif mugkin sehingga siswa dapat terhibur, kemudian siswa kembali konsentrasi dan semangat dalam mengikuti proses pembelajaran. Terdapat bermacam-macam ice breaking yang diantaranya yaitu; tepuk tangan, games atau permainan, audio visual, strory telling, menyanyi, dan gerak badan.

Beberapa ice breaking diatas ada yang membutuhkan media dalam pelaksanaannya, ada juga yang tidak membutuhkan media. Guru dapat mengembangkan dengan semaksimal mungkin sehingga sesuai dengan kebutuhannya. Ice breaking dapat dikemas untuk meriew materi yang telah disampaikan oleh guru. Hal tersebut agar materi pelajaran dan materi dalam ice breaking dapat salig berkesinambungan.

Berikut beberapa ice breaking yang dikembangkan oleh penulis. Ice breaking disini dapat digunakan untuk mengemabangkan keterampilan bahasa siswa. terdapat empat keterampilan (maharah)dalam bahasa Arab diantaranya yaitu; menyimak (maharat al-istima'), berbicara (maharat al-kalam), membaca (maharat al-qiroah), dan menulis (maharat alkitabah).Penulis memilih empat keterampilan yang menjadi titik dalam pembahasan tersebut sebab Belajar berbahasa hakikatnya adalah belajar keterampilan berbahasa (maharat al-lughah), yaitu menyimak (maharat alistima'), berbicara (maharat al-kalam), membaca (maharat al-qiroah), dan menulis (maharat al-kitabah) ${ }^{47}$

Berbagai macam ice breaking yang disebutkan diatas, penulis memiliki beberapa media yang dapat digunakan dalam pembelajaran bahasa Arab. Pembelajaran yang dimaksudkan disini adalah pembelajaraan empat keterampilan (maharah) bahasa, diantaranya adalah menyimak (maharat al-istima'), berbicara (maharat al-kalam), membaca (maharat al-qiroah), dan menulis (maharat al-kitabah).

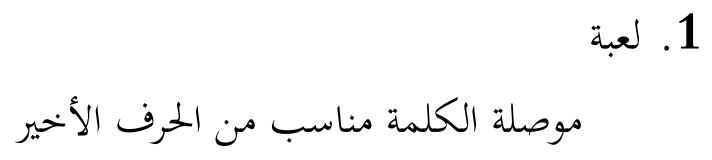

47 Acep Hermawan, Pembelajaran Keterampilan Berbahasa Arab Dengan Pendekatan Komunikatif-Interaktif. (Bandung: Alfabeta, 2018). Hal 12. 


\begin{tabular}{|c|c|c|}
\hline درس & .11 & هذا \\
\hline سرّير & .12 & ذالك \\
\hline رمادي & .13 & كتاب \\
\hline يعمل & .14 & باب \\
\hline لك & .15 & برتقال \\
\hline كرسي & .16 & لون \\
\hline يدرس & .17 & نحن \\
\hline سيد & .18 & نظر \\
\hline دراجة & .19 & رقم \\
\hline تلميذ & .20 & مسجد \\
\hline
\end{tabular}

ب. الهدف : : ممارسة للتلميذ عن المهارة الكلام ج.

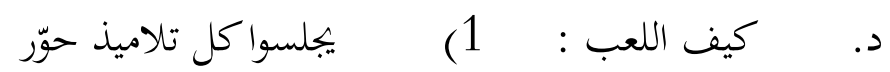
2) يبتدأ أحد التلاميذ بذكر المفردة

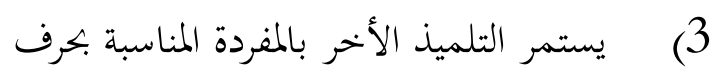

$$
\text { الأخير }
$$

4 ) لم يجز ان يكتب المفردة المناسب

$$
\text { 2. } \begin{gathered}
\\
\\
\end{gathered}
$$




$$
\text { 5. }
$$

$$
\text { أ. المطلوب : كرة }
$$

ب. هدف : ممارسة للتميذ عن المهارة الكلام

$$
\text { د. ج. }
$$

2) يرم المدرس الكرة إلى تلميذ بيذكر المفردة

3) يرم التلميذ كراة إلى التلميذ الأخرى بيذكر لمرن

$$
\text { المفردة. }
$$

$$
\text { بوقتى } 5 \text { ثواني }
$$

4) إذا لايذكر تلميذ المفردة، فيرجعه إلى الكرسي لواي

$$
\begin{aligned}
& \text { 3. } \\
& \text { ينقل القصة بنسابت المفرادة } \\
& \text { أين } \\
& \text { القلم في الحقيبة، الكتاب على المكتب } \\
& \text { المصباح فوق الكرسي، المقلمة تحت الكرسي } \\
& \text { المصلى أمام الملعب، المسجدد وراء الفصل }
\end{aligned}
$$

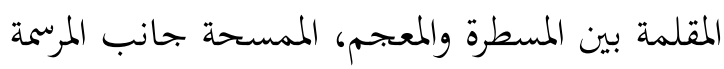

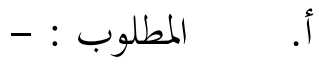

$$
\begin{aligned}
& \text { ب. هدف : ممارسة للتلميذ المهارة الكلام }
\end{aligned}
$$

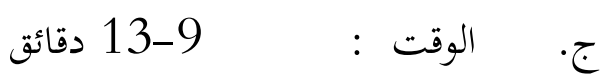

$$
\begin{aligned}
& \text { د. كيف اللعب : 1 1) يجلسواكل تلاميذ حور } \\
& \text { 1. يبتداء احدكم التلاميذ بكتبة المفردة }
\end{aligned}
$$

48 Tim penyusun, Buku Siswa Bahasa Arab Pendekatan Saintifik. (Jakarta: Kemenag ,2013). Hal. 44. 


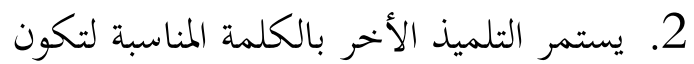

جملة كميلة

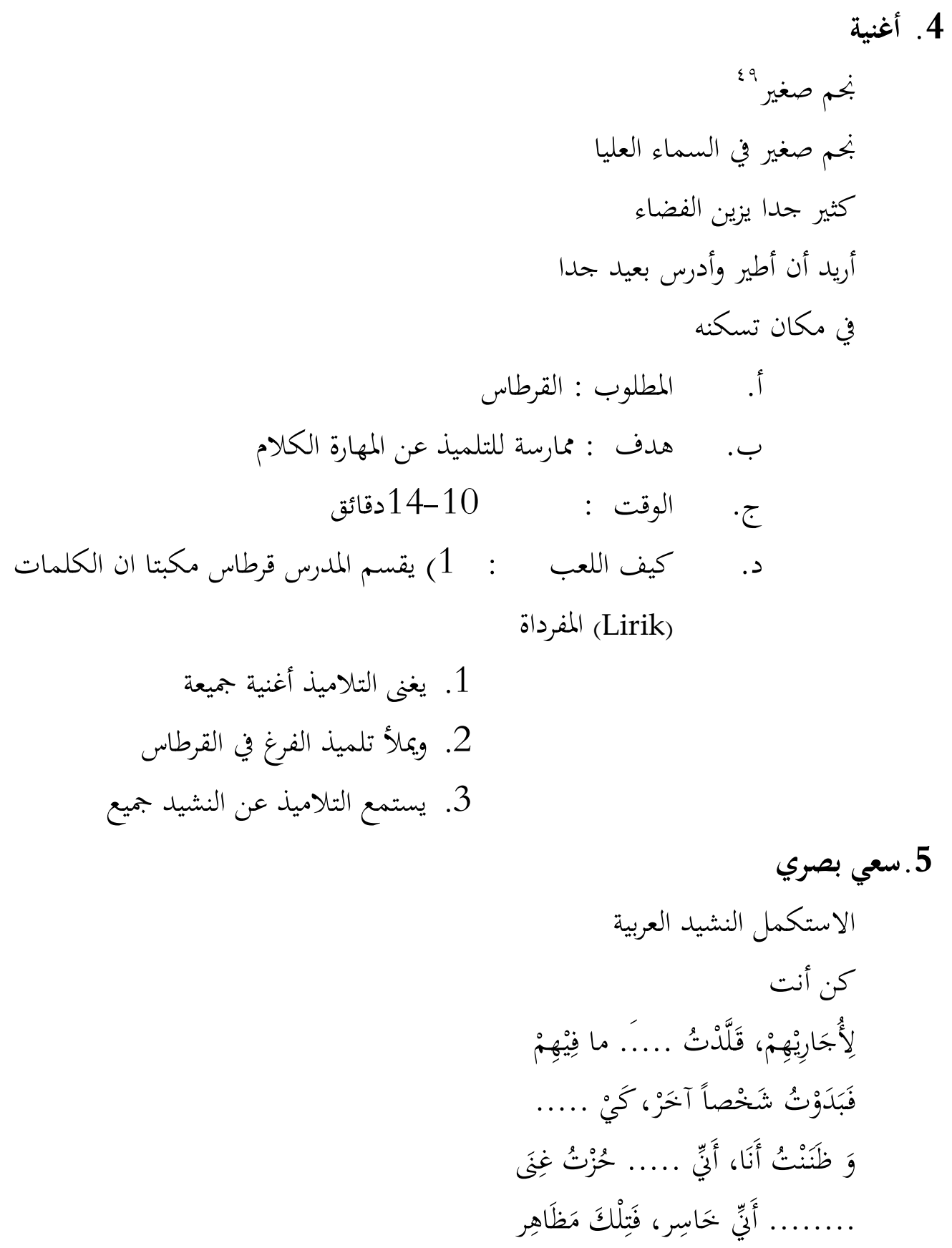

${ }^{49}$ R. Umi Baroroh, Lagu Sebagai Model Pembelajaran Bahasa Arab Untuk Anak dan Pemula. (Yogyakarta: Pustaka Zeedny, 2011). Hal. 48. 


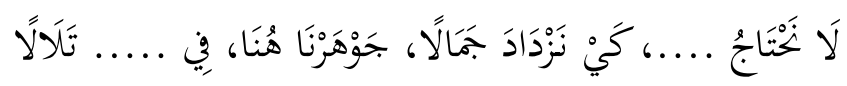

لَ

نُرْضِي النَّاسَ بِمَا لَا، نَرْضَاهُ لَنَا حَالَا، ذَاكَ ........ يَسْمُو يَتَعَالَّل

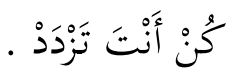

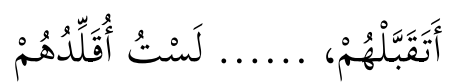

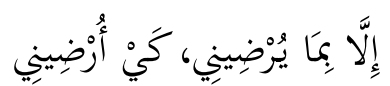

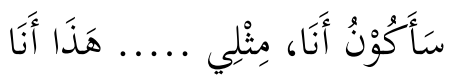

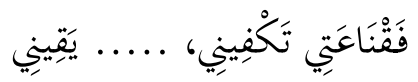

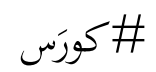

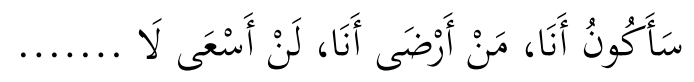

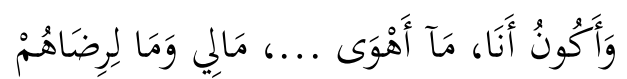

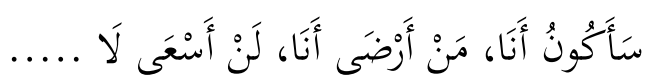

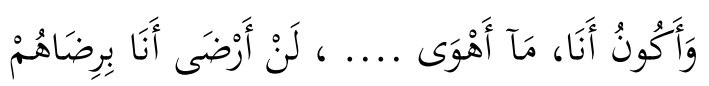
by:مود الخضر

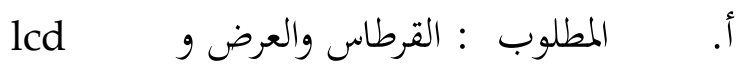
ب. هدف : ممارسة لتلميذ المهارة الكتبة والاستماع

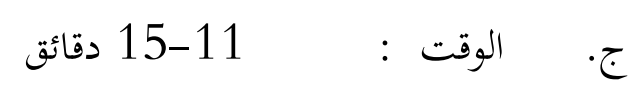
د. كيف اللعب : 1 1) يقسم المدرس قرطاس مكتبا ان الكلمات (lirik)

$$
\text { النشيد ولكن كلمته غير كمل }
$$

2) يقرأ تلاميذ الكلمات في القرطاس

3) يستمع تلاميذ عن النشيد جميع

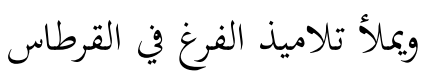




\section{Kesimpulan}

Dari pembahasan diatas dapat diambil kesimpulan bahwa dalam penyampaian ice breaking. Guru dapat mengaitkannya dengan empat keterampilan bahasa (maharah al-lughawi): menyimak (maharat al-istima'), berbicara (maharat al-kalam), membaca (maharat al-qiroah), dan menulis (maharat al-kitabah).

Hasil analisis media ice breaking dalam pembelajaran bahasa Arab. Maka dapat disimpulkan sebagai berikut:

a. Permainan (sambung kata sesuai huruf akhir)

Permainan tersebut menuntut peserta didik untuk menyebutkan kata sesuai huruf akhir yang disebutkan oleh teman sebelumnya. Seperti begitu seterusnya. Permainan ini bertujuan untuk mengasah mufrodat yang dimiliki peserta didik serta untuk melatih maharah kalam dan maharah istima' mereka.

b. Gerak badan (melempar bola sambil menyebut mufrodat)

Gerak badan tersebut menuntut peserta didik untuk menyebut mufrodat sesuai dengan satu yang sama. contohnya : الأسرة

Siswa diminta untuk berdiri melingkar. Guru melempar bola kepada salah satu peserta didik sambil mnyebutkan salah satu anggota keluarga. Kemudian peserta didik tersebut juga melempar bola kepada temannya yang lain sambil melempar bola, begitu seterusnya. Gerak badan tersebut bertujuan untuk melatih maharah kalam peserta didik.

c. Story telling (Sambung kalimat sesuai dengan satutema)

Ice breaking ini menuntut siswa untuk menyebutkan kalimat sesuai dengan mufrodat yang telah tertulis di dalam kartu yang kelompok mereka pilih. Seperti أين tertulis dalam salah satu kartu yang dipilih oleh siswa. Maka kelompok tersebut harus bersambung cerita tentang topik tersebut. Ice breaking ini melatih siswa dalam maharah kalam.

d. Menyanyi

Ice breaking ini menuntut siswa untuk melafalkan lagu berbahasa Arab secara bersama-sama. Seperti lagu Ice breaking tersebut melatih maharah kalam siswa.

e. Audio visual (Mengisi bait kosong pada lirik lagu)

Ice breaking ini menuntut siswa untuk berkonsentrasi dalam mendengarkan lirik lagu yang ditampilkan oleh guru di lcd. Seperti lagu yang berjudul siswa diminta untuk mengisi lirik lagu yang kosong. 
Ice breaking ini melatih maharah qiroah siswa, sebab mereka harus membaca lirik lagu tersebut. kemudian mereka diberi waktu untuk mendengarkan lagu yang melatih maharah istima mereka. Dan terakhir menuliskan lirik lagu pada lirik yang kosong untuk melatih maharah kitabah mereka.

\section{Daftar Pustaka}

Arsyad. Azhar. 2002. Media Pembelajaran. Jakarta: PT. Raja Grafindo Persada

Darmansyah. 2010. Strategi Pembelajran Menyenangkan dengan Humor. Jakarta: Bumi Aksara

De Porter, Bobbi dan Mike Hemmacki. 2001. Quantum Learning: Membiasakan Belajar Nyaman dan Menyenangkan. Bandung: Kaifa

Farida, Anna Dkk,. 2012. Sekolah yang Menyenangkan: Metode Keatif Mengajar Dan Mengembangkan Karakter Siswa. Bandung: Nuansa

Hermawan, Acep. 2018. Pembelajaran Keteramilan Berbahasa Arab. Bandung: Alfabeta.

Iriantara, Yosal. 2014. Komunikasi Pembelajaran: Interaktif Komunikatif, dan Edukatif Di Dalam Kelas. Bandung: Simbiosa Rekatama Media.

Latuheru, John D. 1988. Media Pembelajaran Dalam Proses Belajar Mengajar Masa Kini. Jakarta: Depdikbud.

Lucy, Bunda dan Ade Julius R. 2012. Dahsyatnya Brain Smart Teaching. Jakarta: Penebar Plus.

Mulyasa, E. 2011. Menjadi Guru Profesional Menciptakan Pembelajaran Kreatif dan Menyenangkan. Bandung: Remaja Rosdakarya.

Mustofa, Syaiful. 2011. Strategi Pembelajaran Bahasa Arab Inovatif. Malang: UIN -MA Liki Press.

Nur, M. Zainuri. 2010. Ice Breaker!. Yogyakarta: Laksana.

Pranata, David. 2016. Communication Made Easy. Jakarta: Elexmedia.

Rifa, Iva. 2012. Koleksi Games Edukatif Di Dalam dan Luar Sekolah. Yogyakarta: Flash Book. 
Sadiman, Arief S. Dkk. 1909. Media Pendidikan: Pengertian, Pengembangan dan Pemanfaatannya. Jakarta: Rajawali Press.

Setyawan, Sigit. 2015. Kelas Asyik Dengan Games : 30 Games Untuk Pembelajaran. Jakarta: Gramedia.

Shadily, Hasan. 1982. Kamus Inggris Indonesia. Jakarta: PT. Gramedia.

Sunarto. 2012. Ice Breaker dalam Pembelajaran Aktif. Surakarta: Cakrawala Media.

Soenarno, Adi. 2005. Ice Breaker: Permainan Atraktif - Edukatif Untuk Pelatihan Manajemen. Yogyakarta: Andi. . 2007. Ice Breaker: Don't Be Tegang!! Untuk Pelatihan Manajemen. Yogyakarta: Andi Publisher.

Sulistiawan, Bhayu. 2013. Ice Breaker Untuk Pembelajaran Aktif. Surakarta: Yumna Pustaka.

Yunus, Mahmud. tt. Al-Muthala'ah al-Haditsah. Jakarta: Maktabah asSa'udiyah Putra Jakarta.

http://www.thebalance.com 